\title{
SANTA TERESA Y SUS CARTAS, HISTORIA DE LOS SENTIMIENTOS
}

\author{
POR \\ TEÓFAnEs EgIDO \\ Universidad de Valladolid
}

\section{RESUMEN}

Reflexión histórica sobre una dimensión peculiar de santa Teresa de Jesús: la expresión de sus sentimientos en sus escritos, de forma más especial en sus cartas abundantes. El artículo se centra en el sentido del humor, de la alegría, en la importancia de la risa en el lenguaje de santa Teresa y en el sentimiento de ternura con su familia, con su orden, con fray Juan de la Cruz. Se dedica un espacio amplio a la ternura hacia las niñas en sus conventos. Aparece santa Teresa de Jesús como trasgresora de los comportamientos sociales del siglo XVI.

Palabras Clave: Santa Teresa de Jesús. San Juan de la Cruz. Los sentimientos. La risa, el humor. La ternura. La infancia. Siglo XVI.

\section{TERESA OF JESUS AND HIS LETTERS, HISTORY OF THE FEELINGS}

\begin{abstract}
Historical reflection on a peculiar dimension of St. Teresa of Jesus: the expression of her feelings in her writings, particularly in her abundant letters. The article focuses on the sense of humor, the joyfulness, and the importance of laughter in St. Teresa language, and also on the feeling of endearment with her family, with her order, with fray Juan de la Cruz. Ample space is dedicated to the tenderness towards girls in her convents. St. Teresa of Jesus appears as transgressor of 16th century social behaviours.
\end{abstract}

KeY Words: St. Teresa of Ávila. St. John of the Cross. Feelings. Laughter. Humor. Tenderness. Childhood. $16^{\text {th }}$ Century.

$\begin{array}{ll}\text { Recibido/Received } & 30-10-2014 \\ \text { Aceptado/Accepted } & 09-12-2014\end{array}$




\section{INTRODUCCIÓN}

Hacer la historia de los sentimientos es una tarea necesaria hoy en día, no hay duda, pero no resulta fácil llevarla a cabo, y menos aún cuando los sentimientos se sitúan en la época moderna y se refieren a los santos, que han sido, con tanta frecuencia, creación de la hagiografía y de acuerdo con los modelos dominantes. El género de las vidas o, mejor, excelencias, virtudes y milagros, con más interés en las virtudes y en los milagros que en las existencias terrenas, estaba perfectamente definido en sus contornos.

Son conocidas estas realidades, como es conocida la actuación de la fantasía cuando había que acomodar a las condiciones del modelo de santidad a quienes no acababan de cumplir con los requisitos estrictos de la hagiografía y de las mentalidades. Lo acontecido con fray Juan de la Cruz, de familia pobre de solemnidad convertida por los hagiógrafos en pobreza envergonzante, probatoria por tanto de riquezas anteriores; o con santa Teresa de Jesús y su ascendencia limpia inventada, prueban lo que era habitual en aquellos tratamientos hagiográficos. ${ }^{1}$

Valgan estas observaciones elementales para explicar la dificultad de explorar y reproducir la sensibilidad de los santos hagiografiados en el barroco o a partir del barroco (y pensemos que los modelos barrocos de santidad han pervivido con insistencia y actualidad admirables). La imagen del santo tenía que estar reñida con el mundo de los sentimientos, fueran estos cuales fueran. Aquellas espiritualidades, aquellas santidades, dibujadas por los hagiógrafos, tenían como objetivo nada deleznable no solo el ocultar sino también el matar (morti-ficar) los sentimientos como paso previo y compañero constante en los caminos de perfección. Y si no se dominaban y extinguían, no se podían expresar. Salvo, quizá, los negativos, los de tristeza, dolor, hosquedad, la antipatía.

Y de esta suerte, cuando no se dispone de otro tipo de fuentes de información, fuentes personales, no pensadas para la publicación, ni siquiera para la edificación, sino para la comunicación, no es posible, o resulta muy difícil, acercarse a la sensibilidad, a los sentimientos.

Por fortuna, se da esta información en algunos casos, contados pero casi siempre expresivos. Uno de ellos es el de la Madre Teresa de Jesús. Los historiadores de las formas literarias han puesto de relieve el carácter coloquial, el deseo de comunicar y de comunicarse, tan presente en sus escritos. De hecho,

\footnotetext{
${ }^{1}$ Pueden encontrarse referencias a la abundante bibliografía sobre los comportamientos hagiógraficos aplicados a santa Teresa (y a san Juan de la Cruz): Egido López, T. 2000. «Hagiografía y estereotipos de santidad contrarreformista (La manipulación de San Juan de la Cruz)». Cuadernos de Historia Moderna 26: 61- 85. Egido López, T. 1981. «El tratamiento histórico de Santa Teresa. Inercias y revisiones», en T. Egido (dir.), Perfil histórico de Santa Teresa: 13-31. Madrid: Editorial de Espiritualidad.
} 
casi todos los libros suyos tienen este carácter. Lo tienen en mayor medida sus cartas, que serán los materiales en los que nos basaremos de forma primordial en esta reflexión histórica.

No es posible ahora detenerse en tantas peculiaridades del epistolario teresiano. Baste con llamar la atención hacia el valor de las casi quinientas cartas que se han conservado y en la libertad con que en ellas se expresa sin tener que subordinarse a limitaciones de censura (salvo la autoimpuesta en momentos tan peligrosos para sus frailes y para ella) ni a temores inquisitoriales. Durante mucho, demasiado, tiempo, santa Teresa ha estado como secuestrada por los espirituales. Por ello, las cartas, testigos y expresión magistral de la realidad material, incluso corporal, de la cotidianidad, no resultaban tan atractivas, tardaron tanto en ser impresas las que no se perdieron de tantísimas (entre cinco y veinticinco mil) como pudo escribir. ${ }^{2}$

Es posible, gracias a estas fuentes, descubrir el mundo de sentimientos de su autora, de alegrías y tristezas, de sus risas y sus llantos, de la percepción de su cuerpo, de su edad niña, del sentirse «vieja y enferma», de sus simpatías y antipatías (que las tuvo), de sus predilecciones y decepciones. Como es imposible aludir a todos ellos, esta reflexión limitará su mirada a dos expresiones: la del humor y la risa, en primer lugar, y la de la ternura tan característica de aquella mujer.

\section{EL HUMOR Y LA RISA}

Los historiadores conocen de sobra que hasta el siglo xvIII, dentro de los modelos religiosos, incluso en los códigos de actitudes sociales, la expresión de la alegría, del humor, es decir, la risa, estaba vedada como algo inconveniente e incompatible con el lenguaje de la gravedad y, por supuesto y con más motivo, de la santidad. Eran tiempos que habían recibido e incrementado la herencia bajomedieval del rigor como estilo de vida religiosa, como valor absoluto al que se subordinaban todos los demás. Por ello, las reformas de frailes y monjes (que, por cierto, en Castilla seguían el modelo de «las monjas de Tordesillas») eran tanto más apreciadas y favorecidas cuanto más rigurosas se mostraban, porque el rigor tenía que ser exhibido y resultaba hasta rentable. ${ }^{3}$ Aunque no tardaría en evolucionar, en el origen de la reforma descalza de santa Teresa figuraba el rigor como referencia primera del retorno a la Regla carmelitana que ella creía ser la primitiva.

\footnotetext{
${ }^{2}$ Álvarez, T. 2012. Comentarios a las Cartas de santa Teresa de Jesús. Burgos: Monte Carmelo. Bibliografía y repositorio sobre las cartas de santa Teresa: Carmelo de Puzol: http://delaruecaalapluma.wordpress.com/estudios/sobre-sus-obras/cartas/

${ }^{3}$ Un ejemplo, el de la primitiva Congregación benedictina de San Benito el Real de Valladolid: Egido, T. 1990. «Los antiguos monjes de San Benito el Real y su rigor fascinante y rentable», en J. Rivera (coord.), Monasterio de San Benito el Real. VI Centenario (1390-1990): 29-45. Valladolid: Ámbito.
} 
Una de las expresiones señeras del rigor era la ausencia de la alegría, la santificación del llanto, del don de lágrimas, el rechazo del humor y el anatema de la risa. El asesor de la madre Teresa de Jesús tan venerado por ella, del que en la hagiografía hermosa y elocuente dice «que no parecía sino hecho de raíces de árboles» (Vida 27,8), ${ }^{4}$ fray Pedro de Alcántara, conectaba con el ideal de los eremitorios franciscanos de fines del siglo xv, los fundados por fray Pedro de Villacreces, que se había graduado en las mejores universidades, pero que predicaba después que «más aprendí en la celda, llorando en tiniebla, que en Salamanca o en Tolosa o en París estudiando a la candela». Decía su discípulo admirado que «el primer estudio que él enseñaba a sus discípulos era el llorar y aborrecer el estudio de las letras». Lo del llorar era propio de aquellas espiritualidades, incompatibles con la risa como otra de las destemplanzas y relajaciones. ${ }^{5}$

Porque el reír, además de mal visto, de mirarse como señal inequívoca de liviandad y otras cosas (especialmente en las mujeres), en los monasterios de monjas estaba penado. La propia madre Teresa, en las constituciones primeras de por 1567, incluyó entre las culpas leves con sus penas: «Si alguna riere en el coro o hiciere reír a las otras». Se repetirá la misma pena en las Constituciones sucesivas de 1581 y en las siguientes. Se estaba reproduciendo el texto de la Encarnación en esta parte penal de las Constituciones, preteresianas y más rígidas aún, pues no solo se penaba «Si alguna se riere en el coro o fiziere reír a otras», sino también si, en cualquier lugar, alguna «Disolutamente se riyere». ${ }^{6}$

Podrían multiplicarse los testimonios de estos comportamientos. Aducimos como muestra el del convento fundado por la conocida y asesora en algún tiempo de la Madre Teresa, María de Yepes, en Alcalá de Henares. El cronista de la ciudad, en el tomo que le dedica, ensalza los rigores de aquella comunidad que no acabó de simpatizar con la Madre Teresa porque no era tan rígida como esperaban. Entre las monjas estaba, y con influencia en aquel círculo de observantes, María de la Paz. De ella comenta, fascinado: «se dice que tenía don de lágrimas, y que en más de diez años no la vieron reír ni hablar con nadie, sino lo muy forzosísimo, y que también se arrobaba muchas veces».?

\footnotetext{
${ }^{4}$ Las citas de los libros y cartas de santa Teresa remiten todas a la edición crítica: Santa Teresa de Jesús. 2000. Obras. Madrid: Editorial de Espiritualidad.

${ }^{5}$ Textos y contextos de aquel ambiente rigorista: Egido, T. 1983. San Pedro Regalado: Valladolid: Obra Cultural Caja de Ahorros.

${ }^{6}$ Álvarez, T., Fortes, A. y otros. 1995. 40, 92, 358. Constituciones de las carmelitas descalzas (1562-1607). Roma: Teresianum.

${ }^{7}$ Portilla y Esquivel, M. de. 1728. Historia de la ciudad de Compluto, vulgarmente Alcalá de Santiuste y aora de Henares. Parte III: 127. Alcalá: Joseph Espartoso.
} 
La Madre Teresa, que admiraba a fray Pedro de Alcántara, no coincidió ni con los franciscanos de los eremitorios ni con la idea generalizada de que la perfección tenía que seguir los caminos del rigor extremo. Puede decirse, si ello no sonara a anacronismo, que habría sido una transgresora consumada. En primer lugar por el lenguaje, por la presencia de la risa en sus diversas tonalidades; y en segundo término por el sentido del humor expresado con su palabra. «Cayóme harto en gracia» la oferta del pobre de Toledo que ofrecía todo y no tenía nada (Fundaciones $15,6)$. Y la expresión salta por doquier a lo largo de sus cartas: «Me ha caído harto en gracia su carta», (A Mateo de las Peñuelas, marzo 1574). «Cayóme harto en gracia poner la fecha por letras», (A María de San José, 19 nov. 1576). «Harto en gracia me ha caído su andar a pedir, y no acaba de decirme quién es su compañero» (A Jerónimo Gracián: 30 noviembre 1576). «Harto en gracia me han caído las coplas que vinieron de allá» (A María de San José, 9 enero 1577).

Y así se podría seguir. Basten estas muestras para pensar en una santa sin convencionalismos, aunque ella, en sus cartas, fuese un modelo de respeto hacia las formas epistolares (que critica, naturalmente) ${ }^{8}$ Los escritos mayores y las cartas de la Madre Teresa resultan documentos singulares para la historia de la eutrapelia, de la risa, que, como queda apuntado, se miraba, de manera especial en las mujeres, como una señal, una expresión, provocativa, de pecado, de vulgaridad, propia de aldeanos, de campesinos, de bufones, y así lo han trasmitido las artes figurativas. Es la risa culpable.

Pues bien, llama la atención la frecuencia con la que aparece, ya no solamente el caer en gracia sino el reírse en los escritos de la Madre Teresa. Ante el sentido de la honra, «Yo me reía, o me afligía, alguna vez de lo que veía en el mundo, y aun por mis pecados en las religiones: tocar en un puntito de ser menos no se sufre» (Camino de perfección E 26,4). Se ríe de los soñadores en su loa entusiasmada a la eucaristía: «mas tenía tanta devoción y tan viva fe, que, cuando en algunas fiestas oía a personas que quisieran ser en el tiempo que andaba Cristo en el mundo, se reía entre sí, pareciéndole que, teniéndole tan verdaderamente en el Santísimo Sacramento como entonces, que ¿qué más se les daba?» (Camino de perfección E 61,3). En la fundación de Salamanca, en la noche de ánimas se ríe de lo lindo de los miedos en la casa destartalada (dejada por los estudiantes): «Quedamos la noche de Todos Santos mi compañera y yo solas. Yo os digo, hermanas, que, cuando se me acuerda el miedo de mi compañera, que era María del Sacramento (una monja de más edad que yo y harto sierva de Dios), que me da gana de reír» (Fundaciones 19,3).

\footnotetext{
${ }^{8}$ Rodríguez Martínez, L.-Egido, T. 2002. «Epistolario», en A. Barrientos (dir.), Introducción a la lectura de santa Teresa: 611-667. Madrid: Editorial de Espiritualidad.
} 
Se ríe de los miedos a la Inquisición, como cuando le comunican ciertas murmuraciones contra sus proyectos de reforma: «También comenzó aquí el demonio, de una persona en otra, procurar se entendiese que había yo visto alguna revelación en este negocio, e iban a mí con mucho miedo a decirme que andaban los tiempos recios y que podría ser me levantasen algo y fuesen a los inquisidores. A mí me cayó esto en gracia y me hizo reír, porque en este caso jamás yo temí» (Vida 33,5). Se ríe de sí misma y consigo misma: «que me reía de mí»; «estaba riéndome entre mí» (Vida 37,5,7;38,4). No la contentan las metáforas que está utilizando en las Moradas: «Riéndome estoy de estas comparaciones, que no me contentan, mas no sé otras» (7Moradas 2,11).

Y se ríe, quizás es de quien más se ría, del demonio. Ante las discusiones suscitados por su primera fundación: «Quedé bien cansada de tal contienda y riéndome del demonio, que vi claro ser él» (Vida 36.11). Tiene descripciones plásticas del infierno, y las tiene de los demonios, como en aquella representación en la que «quiso el Señor entendiese cómo era el demonio; porque vi cabe mí un negrillo muy abominable, regañando como desesperado de que adonde pretendía ganar, perdía. Yo, como le vi, reíme, y no hube miedo». No los tenía miedo porque contaba con la seguridad del arma que más ahuyentaba al demonio, un arma netamente contrarreformista como era el agua bendita: «De muchas veces tengo experiencia que no hay cosa con que huyan más, para no tornar. De la cruz también huyen, mas vuelven» $(\mathrm{V} 31,4)$.

\section{LAS CARTAS Y EL HUMOR}

Lo anterior pertenece en su casi totalidad a los llamados escritos mayores. Pensados y redactados para los confesores o consejeros espirituales como las relaciones de la vida o para sus monjas, en ellos tiene que contenerse en su lenguaje. Por eso, la expresión más directa de sus sentimientos personales, la menos sometida a la autocensura, es la que se derrama en sus cartas. Es una lástima que no se conservara la que escribía al padre Domíngo Báñez (el amigo entrañable, incluso después de que apareciera el padre Gracián), «que le escribo muy graciosamente; quizá le mostrará la carta», dice a María Bautista, la priora de Valladolid, su prima (14 mayo 1574), que amenaza con sus consejos a la madre Teresa: «Yo le digo que me hace reír cómo dice que otro día dirá lo que le parece de algunas cosas» (30 diciembre 1575). «Que nos ha hecho reír» una carta de la niña Teresita (a María de San José, 9 septiembre 1576). La hacen reír el tan serio Ambrosio Mariano (mediados de octubre 1576), algunas de las respuestas de las monjas a una especie de desafío espiritual (A Lorenzo de Cepeda, 2 enero 1577). Comunica a su íntimo confidente, su hermano Lorenzo, en Avila: «Riéndome estoy cómo él me envía confites, regalos y dineros, y yo cilicios» (17 enero 1577,19$)$. «Riéndome estoy de cómo ha de contar hasta el agua la 
buena supriora», dice a la priora de Sevilla cuando le pide que cargue los gastos a su cuenta» (11 noviembre 1576).

Aconseja reírse de las calumnias andaluzas (a Gracián, 28 febrero 1577). Para que María de San José, la gran amiga priora de Sevilla, que sabe del tormento de escribir cartas de la Madre, valore las que le dirige a ella le dice: «Riéndome estoy de verme cargada de cartas y qué despacio me pongo a escribir cosas impertinentes» ( 9 enero 1577). Es con quien comparte más confianza, humor y, también, enfados. La escribe en una ocasión (28 marzo 1578): «Bueno es eso de Elías; mas como no soy tan letrera como ella, no sé qué son los asirios». En otro momento, después de reiterar el agrado con que recibe sus cartas ( YYo le digo que nunca me cansan, sino que me descansan de otros cansancios»), se ríe: «Cayóme harto en gracia poner la fecha por letras. Plega a Dios no sea por no humillar a no poner el guarismo. Antes que se me olvide: muy buena venía la del padre Mariano si no trajera aquel latín. Dios libre a todas mis hijas de presumir de latinas. Nunca más le acaezca ni lo consienta. Harto más quiero que presuman de parecer simples, que es muy de santas, que no tan retóricas. Eso gana en enviarme sus cartas abiertas» (19 noviembre 1576).

Simples antes que retóricas quiere a sus monjas. Mejor dicho, prefiere que presuman de simples, no de retóricas. Pero hay que matizar en estos criterios de selección como hace ella ante una vocación que no lleva demasiados ducados de dote, y parece que recomendada por su amiga la aristócrata doña Luisa de la Cerda, fundadora de Malagón (27 mayo 1568): «Olvidádoseme había que me ha dicho de una monja nuestro padre, muy lectora y de partes que a él le contenta. No tiene más de doscientos ducados, mas quedan tan solas y es tanta la necesidad, y para monasterio que se comienza, que digo que la lleven. Más la quiero que traer monjas tontas, y si puedo hallar otra como ésta, no traeré ninguna».

No es ya solo que se ría; es que hace reír, sonreír, por su capacidad de sublimar hasta los momentos más amargos de su existencia, de su proyecto, de su salud. Una antología mínima de su epistolario puede ayudar a disfrutar de esa gracia, de este sentimiento de la madre Teresa, de su humor inteligente que encontramos por doquier.

Es lo que sucede con la narración de lo que ella misma denomina «la elección machucada». Está prácticamente confinada en San José de Ávila, y es un tiempo de confrontación dura entre calzados y descalzos. Hay que elegir priora en la Encarnación, y la mayoría se inclinaba porque repitiera la Madre Teresa, opción imposible de aceptar por el provincial de los carmelitas calzados. Lo interesante fue el modo de discurrir de la votación, tal y como lo narra la Madre Teresa (carta a María de San José, 22 octubre 1577): 
«Yo digo a vuestra reverencia que pasa aquí en la Encarnación una cosa que creo que no se ha visto otra de la manera. Por orden del Tostado vino aquí el provincial de los calzados a hacer la elección, ha hoy quince días, y traía grandes censuras y descomuniones para las que me diesen a mí voto. Y con todo esto a ellas no se les dio nada, sino como si no las dijeran cosa votaron por mí cincuenta y cinco monjas; y a cada voto que daban al provincial, las descomulgaba y maldecía y con el puño machucaba los votos y les daba golpes y los quemaba. Y dejólas descomulgadas ha hoy quince días y sin oír misa ni entrar en el coro, aun cuando no se dice el oficio divino, y que no las hable nadie, ni los confesores ni sus mismos padres.

Y lo que más cae en gracia es que otro día después de esta elección machucada volvió el provincial a llamarlas que viniesen a hacer elección, y ellas respondieron que no tenían para qué hacer más elección, que ya la habían hecho. Y de que esto vio, tornólas a descomulgar y llamó a las que habían quedado, que eran cuarenta y cuatro, y sacó otra priora y envió al Tostado por confirmación.

Ya la tienen confirmada, y las demás están fuertes y dicen que no la quieren obedecer sino por vicaria. Los letrados dicen que no están descomulgadas y que los frailes van contra el concilio en hacer la priora que han hecho con menos votos. Ellas han enviado al Tostado a decirle cómo me quieren por priora. Él dice que no, que si yo quiero irme allá a recoger, mas que por priora no lo pueden llevar a paciencia. No sé en qué parará.

Esto es, en suma, lo que ahora pasa, que están todos espantados de ver una cosa que a todos ofende, como ésta. Yo las perdonaría de buena gana si ellas quisiesen dejarme en paz, que no tengo gana de verme en aquella «Babilonia», y más con la poca salud que tengo, y cuando estoy en aquella casa menos. Dios lo haga como más se sirva y me libre de ellas».

En la correspondencia posterior deplora esta situación, los trabajos de «las pobres monjas», la tozudez de sus partidarias, la recia cosa de estar excomulgadas, que «está espantado todo el lugar de lo que han padecido y padecen» (A Don Teutonio de Braganza, 16 enero 1578), hasta que llegue la consecuencia más dolorosa: la prisión, la desaparición de fray Juan de la Cruz.

Otra descripción, y no es la única, que respira alegría es la que narra al padre Gracián un episodio acontecido en el viaje de retorno de Sevilla a Toledo. Fue un viaje grato, posiblemente el más grato, de los pocos gratos que tuvo. Va en compañía de su hermano venido de Indias, de un joven postulante llamado Diego, del amigo generoso Antonio Ruiz. Llevan consigo a la niña Teresita. Viajan en mulo, y, no se olvide, a ella la gustaba más la caballería que el carro. Era buen jinete, diría más tarde el padre Gracián al alabar el arte de cabalgar de la Madre Teresa en mula: «que se sabía tan bien tener en ella e iba tan segura como si fuera en el coche». Se admiraba él, que tenía fama de todo lo contrario y en vilo a la Madre por sus caídas frecuentes y celebradas como comenta Tomás Álvarez y lamentaba la propia Madre: «Yo le digo, le escribía (a mediados de octubre 1575) que me da un enojo de esas sus caídas, que sería bien le atasen para que no pudiese caer. Yo no sé qué borrico es ése, ni para 
qué ha de andar vuestra paternidad diez leguas en un día, que en un albarda es para matar». ${ }^{9}$

Pues bien, en el paso por Malagón escribía la Madre Teresa al Padre Gracián (15 junio 1576):

«He venido buena, que ha sido más acertado que venir en carros, por caminar a la hora que quería y bien regalada de mi hermano... Teresa ha venido dando recreación por el camino y sin ninguna pesadumbre.jOh mi padre, qué desastre me acaeció!, que estando en una parva, que no pensamos teníamos poco, cabe una venta que no se podía estar en ella, éntraseme una gran salamanquesa o lagartija entre la túnica y la carne en el brazo, y fue misericordia de Dios no ser en otra parte, que creo me muriera según lo que sentí; aunque presto la asió mi hermano y la arrojó y dio con ella a Antonio Ruiz en la boca, que nos ha hecho harto bien en el camino; y Diego mucho; por eso déle ya el hábito, que es un angelito».

Las lagartijas, al margen ya de lo anecdótico, le sirven de imagen para expresar los peligros menores en la oración principiante que no debe atarse a «solo cazar lagartijas» (Vida 13,3). Y a ellas recurre nada menos que a las alturas de las Quintas Moradas 1,5, escritas poco después del accidente de la parva: «Porque, aunque no hay tanto lugar para entrar las cosas emponzoñosas, unas lagartijillas sí, que, como son agudas, por doquiera se meten; y aunque no hacen daño, en especial si no hacen caso de ellas, como dije, porque son pensamientillos que proceden de la imaginación y de lo que queda dicho, importunan muchas veces. Aquí, por agudas que son las lagartijas, no pueden entrar en esta morada».

Y para terminar este apartado con algo menos elevado: en el mismo escenario, en Malagón, pero unos trece años más tarde, cuenta a Gracián (12 diciembre 1579) el traslado de la comunidad a la casa nueva: «El día de la Concepción pasaron estas hermanas a la casa nueva. Fue la pasada con mucho regocijo, porque vinieron en procesión y con el Santísimo Sacramento que se trajo de la otra. Hanse holgado mucho, que no parecían sino lagartijas que salen al sol en verano».

\section{LA TERNURA}

$\mathrm{Si}$, generalizando en exceso, puede decirse que la alegría no entraba en el modelo barroco de santidad, con más motivo hay que decir que la ternura tardaría en aparecer en la mayor parte de sus expresiones. Al igual que la risa, no estaría bien vista hasta que se vayan imponiendo los valores de la Ilustración.

\footnotetext{
${ }^{9}$ Gracián, J. 1982. Escolias a la vida de santa Teresa compuesta por el P. Ribera: 413 (J. L. Astigarraga, ed.). Roma: Teresianum.
} 
Se miraba, y más cuando de santos se trataba, como otra debilidad en el mejor de los casos. O sea, que en la sociedad del tiempo de santa Teresa la ternura, el cariño, eran inexistentes o muy excepcionales, así, en general.

No puede hablarse propiamente de amor matrimonial dado el sentido del matrimonio, no valorado hasta el siglo XVIII, contraído (es decir, contractuado) por los padres o tutores, no por amor entre los contrayentes puesto que no se daba el noviazgo propiamente dicho. A este propósito, son significativas las acepciones de novio (mejor, de no-vió) en el Tesoro de la lengua castellana, e interesantes las descripciones que en el libro nupcial de las Cuartas Moradas 4,5 se ofrecen de los conciertos, de las vistas, del tomarse las manos, etc. El casamiento tenía que ser entre iguales, más aún cuando se trataba de aristocracias, y no era apreciado socialmente quien se había casado, caso raro, «por amores», como se decía despectivamente de alguno que cometió tamaña osadía. En mentalidades tridentinas, no hay duda (una vez que en el concilio se definió que el estado de perfección era el de virginidad, el de las órdenes religiosas anatematizadas por Lutero), el matrimonio era menospreciado en cierto sentido. Como diría el franciscano de más tarde, a principios ya del siglo xVIII, Antonio Arbiol, en su Familia regulada tan impresa y reimpresa:

«No se puede decir mal del santo sacramento del matrimonio; antes bien, importa sepan todos que es error afirmar que el matrimonio es malo, y quien tal dijese debería ser acusado al Santo Tribunal de la Inquisición. No es malo el matrimonio, pero los que se casan son dignos de mucha compasión. Esto quieren decir aquellas misteriosas palabras del Apóstol San Pablo, cuando, hablando de los que se casan, dice: Yo me compadezco de vosotros. Había dicho antes el Santo Apóstol que los que se casan padecerán tribulación. Y dice San Agustín que San Pablo no explicó por extenso las tribulaciones y trabajos que regularmente pasan los que se casan, temiendo que si todas las supiesen, ninguno se casaría. Por eso calla el Apóstol las molestias y tribulaciones en particular de los casados». ${ }^{10}$

Obedece a otros planteamientos la convicción teresiana de las ventajas de ser monja al comparar su situación con la de las casadas. ${ }^{11}$ Pero no se pierda de vista que equivaldría a un anacronismo flagrante creer que santa Teresa vivió en un sistema de valores postilustrado. Por ese motivo resultan más llamativas su actitud y su palabra rebosantes de ternura.

${ }^{10}$ Arbiol, A. (1715). La familia regulada, con doctrina de la Sagrada Escritura y Santos Padres de la Iglesia Católica, para todos los que regularmente componen una casa, a fin de que cada uno en su estado y en su grado sirva a Dios Nuestro Señor con toda perfección y salve su alma: libro 2, capítulo 17. Zaragoza: Herederos de Manuel Román.

${ }^{11}$ Información completa sobre nuevos planteamientos a este respecto: Atienza, A. 2012. «El mundo de las monjas y de los claustros femeninos en la Edad Moderna. Perspectivas recientes y algunos retos», en E. Serrano Martín (coord.), De la tierra al cielo. Líneas recientes de investigación en Historia Moderna (Ponencias). I Encuentro de Jóvenes Historiadores en Historia Moderna: 89-108. Zaragoza: Institución «Fernando el Católico».

Hispania Sacra, LXVII

136, julio-diciembre 2015, 401-428, ISSN: 0018-215X, doi: 10.3989/hs.2015.012 
TERNURA FAMILIAR

Los hagiógrafos, desde el primero de ellos, el valiosísimo Francisco de Ribera en su libro ajetreado, hasta prácticamente ayer mismo, abrían sus «vidas» de santa Teresa proclamando la limpieza de sangre, la condición cristianovieja de su familia. Como juraba un testigo en los procesos de beatificación (en 1610), D. Francisco de Valderrábano, de las elites abulenses, hijodalgo notorio, del hábito de Santiago: «Los padres (de la Madre Teresa) nombrados en el artículo fueron notorios hijosdalgo, cristianos viejos libres de toda raza y mancha de moros, judíos y penitenciados por el Santo Oficio, y por tales habidos e tenidos y comúnmente reputados. Y ansí demás de lo dicho lo ha oído decir a otras personas graves y ancianas desta ciudad que tienen noticia de las cosas antiguas de ella». Lo mimo, al pie de la letra, declaraba su esposa, que vivió siete años con doña Teresa de Ahumada en la Encarnación. ${ }^{12}$

Este capítulo de la alteración, nada ingenua, del linaje de santa Teresa es bien conocido, está ya más que superado y obedecía a unas mentalidades colectivas que no podían ni imaginarse una santa, o un santo, que no fueran limpísimos de sangre. Se ha especulado, quizá en demasía, acerca del influjo de esta condición en los escritos y en las actitudes de la Madre Teresa. A ella la traía muy sin cuidado. Al menos así aparece al hablar de los padres y de los hermanos nada más empezar el libro de su vida. Es claro, se interprete como se interprete, que ella prefería consignar otros valores: «El tener padres virtuosos y temerosos de Dios me bastara, si yo no fuera tan ruin, con lo que el Señor me favorecía, para ser buena». Y recuerda la sinceridad, la lealtad, el bien hablar y nunca jurar, sobre todo la caridad de don Alonso, que ni esclavos (que no escaseaban en Ávila) ${ }^{13}$ quiso tener cuando podía haberlos tenido, «y estando una vez en casa una de un su hermano la regalaba como a sus hijos. Decía que de que no era libre, no lo podía sufrir de piedad».

Cualquier observador puede advertir en las palabras autobiográficas con las que se abre el libro de la Vida que se trata de una familia y de una infancia que vivió lo que no se vivía entonces, la ternura. Presenta, en el primer capítulo, con trazos maestros, el estilo de vida de su familia, numerosa, en otro rasgo excepcional entonces: «Éramos tres hermanas y nueve hermanos. Todos parecieron a sus padres por la bondad de Dios en ser virtuosos, si no fui yo, aunque era la más querida de mi padre».

${ }^{12}$ Sobrino Chomón, T. (ed.). 2008. Procesos para la beatificación de la madre Teresa de Jesús. I: 254, 309. Ávila: Institución Gran Duque de Alba.

${ }^{13}$ Tapia, S. de. 2011. «La sociedad abulense en el siglo XVI», en Vivir en Ávila cuando Santa Teresa escribe el libro de su Vida: 69-133. Ávila: Centro Internacional Teresiano Sanjuanista. 
Esto de ser querida, de la ternura (expresión muy teresiana), del cariño (ella no usa todavía esta palabra), asoma ya desde el primer momento. Se sintió querida por sus hermanos, y los quería: «a todos tenía gran amor y ellos a mí», si bien es comprensible su predilección hacia Rodrigo, «casi de mi edad, que era al que yo más quería».

El cariño seguiría a lo largo de su vida, llena de alegrías, de tristezas y de disgustos familiares. Su padre se opuso a que abandonara la casa natal para ir al convento porque «era tanto lo que me quería»; y «acuérdaseme que, cuando salí de casa de mi padre, no creo será más el sentimiento cuando me muera». Emoción, ternura y dolor respira el relato de la reacción ante la muerte de su madre, con la que la relación de amistad filial llegó al extremo de la complicidad en lecturas clandestinas ya que aquélla, en otra excepción, era una familia lectora. Madre e hija se aficionaron a los libros socialmente proscritos de caballería, y «era tan en extremo lo que en esto me embebía, que, si no tenía libro nuevo, no me parece tenía contento».

Llegó la dispersión de prácticamente todos los hermanos a las Indias, y mucho más tarde, cuando andaba ya con su primera fundación de descalzas, escribiría al más afortunado, don Lorenzo de Cepeda (en Quito, 23 diciembre 1561): «No sé cómo me quieren tanto». De nuevo el epistolario permite seguir las cuitas de la familia, los cuidados, las alegrías y los disgustos que proporcionaron a la Madre Teresa sus hermanos y sobrinos.

\section{LA OTRA FAMILIA: LA CARMELITANA}

Los monjes, frailes y monjas, en aquellas sociedades clericales, tenían la convicción de pertenecer a la otra familia, a la religiosa de la orden respectiva. De hecho, el lenguaje del clero regular indicaba esta conciencia al contar con patriarcas, con troncos familiares, en los tratamientos de padres, hermanos, madres, hermanas. El orgullo familiar, las confrontaciones entre órdenes por su antigüedad, por los privilegios, por precedencias, por el patrimonio material y espiritual, por sus clientelas de terciarios y cofrades, eran todos integrantes y reveladores de la intensidad con que se vivía el espíritu de familia, que en ocasiones se superponía o se anteponía al de la familia natural, mirada por algunos como un lastre para el camino de perfección. Quizá no sea del todo desacertado pensar que la familia fue vivida antes en los conventos que en las casas paternas.

La Madre Teresa vivió con pasión el sentimiento familiar de su orden del Monte Carmelo, que estaba convencida de tener como patriarca nada menos que al profeta Elías (las críticas a tales leyendas llegarían algo más 
tarde). ${ }^{14}$ Por volver a aquellos orígenes se empeñarían las reformas carmelitanas medievales fracasadas, la teresiana con fortuna aunque no sin desgarros. Se estableció, por tanto, una relación de maternidad no solo entre las monjas y la fundadora sino también entre los frailes y la Madre.

Las cartas, de nuevo, resultan elocuentes para seguir estos sentimientos. Fueron el medio de comunicación necesario, utilizado con generosidad y en todas las posibilidades de aquel sistema postal, que en tiempo de Felipe II se modernizó. ${ }^{15}$ La mayor parte de las que nos han llegado fueron las dirigidas a sus frailes y monjas, algunos de los cuales tuvieron el cuidado de conservarlas. Los privilegiados, y los predilectos, fueron el padre Jerónimo Gracián y María de San José. El padre Gracián la fascinó por sus valores desde que en 1575 se encontraran en Beas. El cariño fue profundizando a medida que ambos tuvieron que sufrir tanto por la enemiga hacia él y hacia los descalzos, y llega a expresiones de ternura que dan la sensación de que lo mira y lo quiere y lo mima como a un hijo, que a veces responde con algún que otro desdén, con alguna que otra decepción. La otra privilegiada será la madre María de San José, la priora de Sevilla, a la que trata con familiaridad, intimidad de mujer, con plena confianza llena de ternura. También la «priora» ocasionará a la Madre alguna que otra decepción al no corresponder siempre a sus cuidados como ella esperaba. Uno y otra serán los más fervientes y encariñados entusiastas de la Madre Teresa después de muerta. Ambos experimentarían la persecución de los superiores descalzos en tiempos postfundacionales.

La relación de la Madre Teresa con fray Juan de la Cruz fue encantadora. En el verano de 1567, en Medina del Campo, estaba preocupada por la fundación de los descalzos. Tenía licencia del superior general, pero no tenía frailes. Allí mismo se le ofreció el prior de los carmelitas, fray Antonio de Heredia, y comprometió -ella- al jovencísimo fray Juan de Santo Matía, que acababa de ordenarse sacerdote y estaba estudiando en Salamanca. La narración de los encuentros está llena de matices. Ambos andaban con ansias de rigores, pensando en cartujas. Pero del padre Antonio, dice, «no estaba muy satisfecha, aunque me alegraba de oírle», y, de hecho, le impuso una especie de noviciado. En cambio, como diría más tarde «fray Juan de la Cruz contentóme mucho» (Fundaciones 3, 16-17).

\footnotetext{
${ }^{14}$ Egido, T. 2007. «»Nuestro Padre San Elías», en F. Millán Romeral (ed.), In labore requies (homenaje de la Región Ibérica Carmelita a los Padres Pablo Garrido y Balbino Velasco): 205-227. Roma: Edizioni Carmelitane.

${ }^{15}$ Ascandoni Rivero, J. 1999. «El correo durante el reinado de Felipe II», en E. Martínez Ruiz (dir.), Felipe II, la ciencia y la técnica: 253-274. Madrid: Actas. Montáñez Mantilla, M. 1955. El correo en la España de los Austrias, Madrid: CSIC. Alonso García, F. 2004. El correo en el Renacimiento europeo. Estudio postal del archivo Simón Ruiz, Madrid: Fundación Museo de las Ferias.
} 
Alegre por el reclutamiento, dicen algunas relaciones que la Madre comunicó a sus monjas la noticia en recreación: «Sepan, hijas, que tengo ya fraile y medio para dar principio a esta nueva Reformación y estoy muy contenta». Las versiones sobre quién era el fraile y quién el medio fraile no se muestran concordes. Para Gracián, el medio fraile era fray Juan de la Cruz, porque «es pequeño de cuerpo». ${ }^{16}$ Para María Evangelista, que había ingresado en Medina por el tiempo de los acontecimientos y trasmitía la tradición viva de la comunidad, «la dicha Santa Madre tuvo por fraile entero al dicho fray Juan de la Cruz porque se pagó de él más y por tenerle por más a propósito para su intento». ${ }^{17}$ Todo dependía de la estatura a la que pudiera haberse referido, la corporal o la espiritual, y la cuestión sigue sin dilucidarse ya que la Madre Teresa no aclaró el sentido de estas palabras (si es que las pronunció).

Lo cierto es que, para ella, fray Juan de la Cruz era de gran estatura espiritual y de cuerpo pequeño. Lo repite ella con cariño. Cuando iba fray Juan camino del lugarcillo para empezar la reforma masculina, recomendaba al amigo abulense Francisco de Salcedo al portador de la carta: «Hable vuestra merced a este padre, suplícoselo, y favorézcale en este negocio que, aunque es chico, entiendo es grande en los ojos de Dios» (fines de septiembre 1568). Cuando recibió la noticia de que había sido liberado de la cárcel toledana escribía a Gracián (21 de agosto de 1578): "Yo le digo que traigo delante lo que han hecho con fray Juan de la Cruz, que no sé cómo sufre Dios cosas semejantes, que aun vuestra paternidad no lo sabe todo. Todos nueve meses estuvo en una carcelilla que no cabía bien, con cuan chico es, y en todos ellos [no] se mudó la túnica, con haber estado a la muerte».

La prisión de fray Juan, cuando estaba allí mismo, en Ávila, motivó la angustia de la Madre Teresa (que se encontraba también confinada en su convento de San José). Pero también removió su ternura. ${ }^{18}$ Inmediatamente recibió el testimonio escribanil de la desaparición (4 diciembre 1577). Y el mismo día se apresuró a escribir nada menos que al rey Felipe II. Le presenta a fray Juan, «tan gran siervo de nuestro Señor, y así le tienen por un santo, y en mi opinión lo es y ha sido toda su vida». Describe su apresamiento y el del compañero por los calzados: «y tiénenlos presos en su monasterio, y descerrajaron las celdas, y tomáronles en lo que tenían los papeles». Dan una idea de la violencia de aquellas guerras familiares las expresiones de la Madre Teresa a Felipe II: «A mí me

\footnotetext{
${ }^{16}$ Gracián, J. 1982. «Escolias a la Vida de Santa Teresa compuesta por el P.Ribera», en Monumenta historica Carmeli Teresiani, Fontes selecti 3: 388-389. Roma: Institutum Historicum Carmeli Teresiani.

${ }^{17}$ Fortes, A. y Cuevas, FJ. (eds.). 1991, Procesos de beatificación y canonización de san Juan de la Cruz. II: Procesos ordinarios (1614-1618): 156. Burgos: Monte Carmelo.

${ }^{18}$ Álvarez, T. 1990. «La Madre Teresa habla de fray Juan de la Cruz. Repertorio de textos teresianos sobre el Santo», en Federico Ruiz (coord.), Experiencia y pensamiento en san Juan de la Cruz»: 401459. Madrid: Editorial de Espiritualidad.
} 
tiene muy lastimada verlos en sus manos, que ha días que lo desean, y tuviera por mejor que estuvieran entre moros, porque quizá tuvieran más piedad. Y este fraile tan siervo de Dios está tan flaco de lo mucho que ha padecido, que temo su vida. Por amor de nuestro Señor suplico a Vuestra Majestad mande que con brevedad le rescaten».

El preferir la tierra de moros a las manos de los calzados expresa la violencia de aquellas guerras familiares entre frailes. A la semana siguiente comunica a María de San José (10 diciembre 1577): «Y hanlos llevado presos como a malhechores, que me tienen con harta pena hasta verlos fuera del poder de esa gente, que más los quisiera verlos en tierra de moros».

No hay semana, a partir de entonces, en la que no manifieste su preocupación por el prisionero. Se exaspera porque nadie se preocupa de él, ni Gracián (con familiares en la Corte), ni Antonio de Jesús (con favor del duque de Alba), ni el ingeniero del rey Ambrosio Mariano, tan apreciado por la casa de Éboli. Sólo «Doña Guiomar llora a su fray Juan de la Cruz y todas las monjas. Cosa recia ha sido ésta» (A Gracián, 15 abril 1578). «No sé qué ventura es que nunca hay quien se acuerde de este santo. A la princesa de Éboli que lo dijese Mariano, lo haría», escribe a Gracián (19 agosto 1578) cuando hace ya algunos días que fray Juan ha abandonado la cárcel.

Fue la incertidumbre, la desinformación, lo que más la inquietó. No sabe dónde le han llevado: «Mi pena es que los llevaron y no sabemos adónde. Mas témese que los tienen apretados, y temo algún desmán», comunica al obispo amigo Don Teutonio de Braganza (16 enero 1578). Casi medio año ha pasado, y confía a Gracián (22 mayo 1578) su preocupación: «Espantada estoy de este encantamiento de fray Juan de la Cruz». «No creerá, hija, la pena que tengo, porque a mi padre fray Juan de la Cruz lo han desaparecido, y no hallamos rastro ni luz para saber adonde está», dice apenada a Ana de Jesús, pidiendo rogativas (agosto, 1578).

A pesar de que alguna monja atestiguase, más de treinta años más tarde, que la Madre se había enterado del lugar de la prisión, lo cierto es que no lo supo. Ana de San Bartolomé, que en los días aciagos era enfermera-secretaria de la Madre y que sería su más fiel confidente, cuando recuerde aquellas angustias («y más por no entender ni saber dónde lo habían llevado»), se admira en su ingenuidad de que «Nuestro Señor que en cosas más fáciles la descubría, y en ésta en nueve meses no supo dónde estaba el buen padre fray Juan de la Cruz que ella tanto quería». ${ }^{19}$

${ }^{19}$ Ana de San Bartolomé. 1981. «Noticias sobre los comienzos del Carmelo Teresiano», en Urkiza, J. (ed), Obras completas de la beata Ana de San Bartolomé, I: 62. Roma: Teresianum. 
Después de salir de la cárcel, fray Juan sigue preocupando a la Madre. Ha quedado muy débil, y teme por su vida. Lo han llevado a un capítulo especial, a Almodóvar del Campo, y pide a Gracián (mediados de septiembre 1578) que cuide de fray Juan, extenuado: «Harta pena me ha dado la vida que ha pasado fray Juan, y que le dejasen estando tan malo ir luego por ahí. Plega a Dios que no se nos muera. Procure vuestra paternidad que lo regalen en Almodóvar. Mire no se le olvide. Yo le digo que quedan pocos a vuestra paternidad como él, si se muere».

Tenía la Madre interés en que no lo llevaran a Andalucía, tan temida por ella. No la hicieron caso, y lo recomienda a la priora de Beas con encomios entrañables: «que es un hombre celestial y divino. Pues yo le digo a mi hija que después que se fue allá no he hallado en toda Castilla otro como él, ni que tanto fervore en el camino del cielo. No creerá la soledad que me causa su falta... Miren que es un gran tesoro el que tienen allá en ese santo» (A Ana de Jesús, mediados de noviembre de 1578). ${ }^{20}$

Después de la separación de los descalzos, en tiempos de más bonanza (2324 de marzo de 1581), pedía al provincial la Madre, además «en hornazo», que sacara de Andalucía a fray Juan. Naturalmente no la hizo caso Gracián, ni parece que fray Juan estuviese tan a disgusto por aquellas tierras; más bien sucedía todo lo contrario.

El empeño de la Madre Teresa se explica por sus deseos de tenerle cerca, quizá recordando la larga temporada durante la cual estuvieron en el monasterio de la Encarnación. Lo cierto es que la familiaridad entre ambos llegaba a las bromas. Cuenta ella misma en una de sus relaciones espirituales: «Estando en la Encarnación el segundo año que tenía el priorato, octava de San Martín, estando comulgando, partió la forma el padre fray Juan de la Cruz que me daba el Santísimo Sacramento para otra hermana. Yo pensé que no era falta de forma, sino que me quería mortificar, porque yo le había dicho que gustaba mucho cuando eran grandes las formas (no porque no entendía no importaba para dejar de estar el Señor entero, aunque fuese muy pequeño pedacico). Díjome su Majestad: No hayas miedo, hija, que nadie sea parte para quitarte de mí» (Cuenta de conciencia, Ávila, 18 de noviembre de 1572).

Más tarde, ya hacia el final de la estancia de fray Juan en Ávila, tuvo lugar el «vejamen», especie de acertijo espiritual a ver quién daba con la exégesis certera de la locución «búscate en mí». Las respuestas del círculo de Ávila provocaron el dictamen de la Madre, que las va enjuiciando con ironía encantadora. De la del caballero Francisco de Salcedo comenta: «Y lo peor de todo es que si no se

\footnotetext{
${ }^{20}$ Para este tiempo y estas cartas, Pacho, E. 1998. «Desde Toledo al Calvario». Teresianum 49: 607-649.

Hispania Sacra, LXVII

136, julio-diciembre 2015, 401-428, ISSN: 0018-215X, doi: 10.3989/hs.2015.012
} 
desdice habré de denunciar de él a la Inquisición, que está cerca. Porque después de venir todo el papel diciendo: esto es dicho de San Pablo y del Espíritu Santo, dice que ha firmado necedades. Venga luego la enmienda; si no, verá lo que pasa». A su hermano Lorenzo de Cepeda: «que si ha dicho más que entiende, por la recreación que nos ha dado con ellas, le perdonamos la poca humildad en meterse en cosas tan subidas, como dice en su respuesta». Al capellán Julián de Ávila: «Yo le perdono sus yerros, porque no fue tan largo como mi padre fray Juan de la Cruz», del que comenta: «Harto buena doctrina dice en su respuesta para quien quisiere hacer los ejercicios que hacen en la Compañía de Jesús, mas no para nuestro propósito. ¡Caro costaría si no pudiésemos buscar a Dios sino cuando estuviésemos muertos al mundo!...Dios me libre de gente tan espiritual que todo lo quieren hacer contemplación perfecta, dé do diere. Con todo, los agradecemos el habernos tan bien dado a entender lo que no preguntamos». ${ }^{21}$

Para cerrar este apartado, tiene su encanto el ver cómo en la fundación de Medina del Campo, en los libros de cuentas de la comunidad, en febrero de 1570 se anota: «para Catalina, de unos zapatos, miércoles, se gastó tres reales y doce maravedís»; en diciembre del mismo año: «para Catalina y más, de unos zapatos, cuatro reales». Y lo más expresivo es que la Madre Teresa, nombrada priora muy efímera en aquel convento, firmaba ella misma la cuenta de agosto del año siguiente: «Hoy, sábado, de gasto en miel y aceite y arroz y guebos, y unos zapatos para Catalina, diez y siete reales y doce maravedís». Esta Catalina era la madre de fray Juan y una pobre de solemnidad, censada como tal en la Villa. Esta pobreza de solemnidad, estudiada ejemplarmente y con rigor histórico por Alberto Marcos, ${ }^{22}$ es una de las claves de comprensión de Juan de Yepes, pero lo que interesa resaltar ahora es cómo era atendida generosamente (el gasto en zapatos parece considerable) por la propia Madre Teresa y por su comunidad medinense, que dio a la viuda pobre, al enterrarla en su claustro en el año del catarro universal de 1580 , lo más preciado en aquellas sociedades sacralizadas que valoraban más la muerte que la vida y que estimaban como el mejor signo de prestigio los funerales y el lugar de la sepultura. ${ }^{23}$

\section{Las niñas de los conventos de la Madre Teresa}

No se ha insistido en el significado de la presencia de las niñas en las fundaciones de la Madre Teresa, sensible a esta expresión excepcional de ternura. Es de sobra conocido por la historia de la infancia cómo hasta el siglo XvIII no puede

\footnotetext{
${ }^{21}$ Santa Teresa de Jesús. 2000: 1191-1194.

${ }^{22}$ Marcos Martín, A. 1993. «San Juan de la Cruz y su ambiente de pobreza», en Actas del Congreso Internacional Sanjuanista, Tomo II: Historia: 143-184. Valladolid: Junta de Castilla y León.

${ }^{23}$ Rodríguez, J. V. 2012. San Juan de la Cruz. La biografía: 413-415. Madrid: San Pablo.
} 
hablarse del cariño en las relaciones paternofiliales. Los factores demográficos, sobre todo los cambios de sensibilidad en la Ilustración, explican este otro cambio sustancial en los comportamientos colectivos. Propiamente, la niñez ni existía antes en la valoración social, y la crianza de los hijos lo era, como rezaba el catecismo, para el cielo, porque importaba mucho más asegurar la vida eterna («para siempre, siempre, siempre») de la criatura que la supervivencia temporal. Salvo casos muy excepcionales, no se lloraban las muertes (tan frecuentes) de los niños, menos aún las de las niñas.

Puede verse un ejemplo del escaso aprecio, de la inexistente ternura, hacia los niños, hacia las niñas en concreto, en las palabras tan intencionadas de la Madre Teresa cuando traza la historia de la fundadora de Alba de Tormes (Fundaciones 20, 2-5). Lo aducimos en su integridad y en su largura por su crítica social, por esas asimilaciones entre hijos-padres-infierno e hijas-madres-cielo:

«Fue hija Teresa de Layz, la fundadora del monasterio de la Anunciación de nuestra Señora de Alba de Tormes, de padres nobles, muy hijos de algo y de limpia sangre. Tenían su asiento, por no ser tan ricos como pedía la nobleza de sus padres, en un lugar llamado Tordillos, que es dos leguas de la dicha villa de Alba. Es harta lástima que, por estar las cosas del mundo puestas en tanta vanidad, quieren más pasar la soledad, que hay en estos lugares pequeños, de doctrina y otras muchas cosas, que son medios para dar luz a las almas, que caer un punto de los puntos, que, esto que ellos llaman honra, traen consigo.

Pues, habiendo ya tenido cuatro hijas, cuando vino a nacer Teresa de Layz, dio mucha pena a sus padres, de ver que también era hija. Cosa cierto mucho para llorar, que, sin entender los mortales lo que les está mejor, como los que del todo ignoran los juicios de Dios, no sabiendo los grandes bienes que puede venir de las hijas ni los grandes males de los hijos, no parece que quieren dejar al que todo lo entiende y los cría, sino que se mata por lo que se habían de alegrar... Cuán diferente entenderemos estas ignorancias en el día adonde se entenderá la verdad de todas las cosas, y cuántos padres se verán ir al infierno por haber tenido hijos, y cuántas madres, y también se verán en el cielo por medio de sus hijas!

Pues, tornando a lo que decía, vienen las cosas a términos, que, como cosa que les importaba poco la vida de la niña, a tercer día de su nacimiento se la dejaron sola, y sin acordarse nadie de ella desde la mañana hasta la noche. Una cosa habían hecho bien: que la habían hecho bautizar a un clérigo luego en naciendo. Cuando a la noche vino una mujer que tenía cuenta con ella, y supo lo que pasaba, fue corriendo a ver si era muerta, y con ella otras algunas personas que habían ido a visitar a la madre, que fueron testigos de lo que ahora diré. La mujer la tomó llorando en brazos, y le dijo:-Cómo, mi hija? Vos, ¿no sois cristiana?, a manera de que había sido crueldad. Alzó la cabeza la niña, y dijo: -Sí soy. Y no habló más hasta la edad que suelen hablar todos».

No estará de más aducir otro argumento, probatorio éste de que la ternura maternofilial estaba subordinada a otras motivaciones. La aduzco por tratarse de la ya mencionada María de Yepes, la analfabeta hija de un relator de la Chancillería de Granada. Beata carmelita, se empeñó en fundar un convento reformado que siguiese la regla primitiva, la anterior a la relajación. Necesitaba

Hispania Sacra, LXVII

136, julio-diciembre 2015, 401-428, ISSN: 0018-215X, doi: 10.3989/hs.2015.012 
licencias pontificias, y la beata no sólo dejó Granada para ir personalmente a Roma sino también a un hijito de ocho años que salió corriendo detrás de la madre. Dice el hagiógrafo, admirado y admirador, «la madre valerosa, sin mostrar flaqueza de mujer ni ternura de madre, se llegó a una tienda, compró algunas bugerías de niños, unos zapatos pintados, y se lo dio diciendo: corred, hijo, a casa de tía, y decidle que os los calce y guise la comida, que yo voy luego». Pero no volvió ni la cabeza (recordando a la mujer de Lot), como dice fascinado el cronista de la vida de otra mujer mucho más extraña aún, ${ }^{24} \mathrm{y}$ en vez de ir a fundar en Granada, donde inicialmente pensaba establecer su convento riguroso, lo hizo, como hemos visto, en Alcalá de Henares, quince días después del de San José de Ávila por la Madre Teresa, que habla de ella, sin decir su nombre, en el capítulo 35 del libro de su Vida.

Sirva lo anterior como especie de introducción, muy elemental por cierto, a lo que ahora nos importa: la inhabitual ternura de la Madre Teresa hacia las niñas necesitadas de cariño por ser huérfanas familiares o de madres tan amigas como si fuesen parientes, y para que se criaran en sus conventos.

\section{Doña Casilda de Padilla}

La primera niña en un monasterio teresiano fue doña Casilda de Padilla, y su aventura ocasionó una pieza literaria de primer orden, los capítulos 10 y 11 del libro de las Fundaciones con la descripción hermosa y plástica del empeño y artimañas de la niña de los chapines. Narra la Madre la entrada de Casilda en el convento de Valladolid contra la voluntad de su familia aristócrata, que, para asegurar la transmisión de títulos preciados, la quería casar con su tío, ya mayor, y de hecho con él la desposaron a los once años. Sus deudos consiguen que retorne a su familia, pero de forma efímera: la niña volverá al convento, y desde aquellos primeros meses de 1574 las cartas de la Madre Teresa hablan sin cesar de «ese ángel» (a Domingo Báñez, principios de enero 1574), de «la mi Casilda» (a la priora de Valladolid, 14 mayo 1574), «mi querida Casilda, por no la ver también pesa» (a id. 11 septiembre 1574).

Tres años más tarde, con catorce, se conseguirá la dispensa pontificia para la profesión de Casilda, «que está alegrísima», y pide al superior y a la priora que no la retrase, «porque no se esté deshaciendo aquel angelito» (A Gracián, 4 noviembre 1576); «dé prisa a su profesión; no se alargue más, que es para matarla» (A María Bautista, 16 diciembre 1576). Profesa en enero de 1577, y la Madre Teresa

${ }^{24}$ Ángel de San Gabriel, De la buena mujer Catalina de Cardona: 84v-85r. Manuscrito 4213, BNM. Citado en Efrén de la Madre de Dios y Steggink, O. 1977. Tiempo y vida de santa Teresa: 371 . Madrid, BAC. 
le da la enhorabuena de esta suerte tan poco frecuente entonces y tan cariñosa: «Y a la mi Casilda un gran abrazo, y que de buena gana se lo diera yo: harto me alegrara hallarme presente» (a la priora de Valladolid, 21 enero 1577).

No tardarán en aparecer los problemas graves, no tanto por Casilda cuanto por sus parientes y por motivos económicos. Y a los cuatro años de profesa, en 1581, salió del convento y de la orden. Por intereses de su madre, de familiares y de algunos «teatinos» que querían su herencia para otros fines, consiguió breve de Roma para pasar a un monasterio, patrimonio de la familia, esta vez de franciscanas concepcionistas en Santa Gadea, luego trasladado a Burgos. Fue muy profunda la decepción de la Madre Teresa, que en todo momento disculpa a Casilda, pero que, cuando comunica a Gracián (17 septiembre 1581) la mala noticia, no calla su convicción: «No debe querer su Majestad que nos honremos con señores de la tierra, sino con los pobrecitos, como eran los apóstoles, y así no hay que hacer caso de ello»; «Vaya con Dios. ¡Él me libre de estos señores que todo lo pueden y tienen extraños reveses!».

Este fue el desenlace. La Madre quiere y excusa a Casilda: «Lástima me hace la pobre Casilda, que el amor que tenía a la orden era cosa grande. No sé qué demonio la ha trabucado. Dios sea con ella». Por su parte, Casilda conservó siempre cariño a la Madre, como se puso de manifiesto a la hora de declarar en su proceso de beatificación (1610). Es elocuente el testimonio que expresa cómo la ternura de la Madre Teresa hacia las niñas de sus conventos, hacia Casilda en concreto, no se expresaba solo con palabras; también con gestos tan maternales, como el que, entre otras cosas, recordaba: que «tuvo tan estrecho trato con la dicha santa Madre; que, siendo de pequeña edad, la abrigaba la santa Madre y dejaba adormecer en su regazo»..$^{25}$

A lo mejor no es del todo inoportuno recordar que doña Casilda murió en 1618, que vivió la beatificación de la Venerable Madre. No se sabe si leería las Fundaciones con las cosas tan estupendas que sobre ella se dicen en capítulos que la autora nunca borró ni arrancó, pero que sí se cercenaron los editores en la primera impresión del libro hecha en Bruselas en $1610 .^{26}$

\section{TeresitA, LA SOBRINA}

Cuando en el verano de 1575 llegó de las Indias su hermano preferido y viudo, don Lorenzo de Cepeda, el único que hizo fortuna allí, con él desembarcaron sus

\footnotetext{
${ }^{25}$ Silverio de Santa Teresa (ed.). 1935. Procesos de beatificación y canonización de santa Teresa de Jesús, III: 416. Burgos: Monte Carmelo.

${ }^{26}$ Información sobre Casilda Padilla y su familia: Álvarez, T. (dir). 2002. Diccionario de Santa Teresa. Doctrina e historia: 1077-1080. Burgos: Monte Carmelo. 
hijos huérfanos de madre. La menor, una niña de ocho o nueve años, a la que el padre había dado el nombre de Teresa por afecto hacia su hermana y que ya sabía leer y escribir, sería acogida en el convento de Sevilla.

Sorprende la ternura que las monjas, y en primer lugar la priora María de San José y la Madre Teresa de Jesús, derramaron con la niña indiana, tan presente en el epistolario de su tía desde su misma llegada, comunicada inmediatamente a su prima la priora de Valladolid (28 agosto 1575): «Ya habrá sabido cómo vinieron mis hermanos en esta flota. Lorenzo de Cepeda es el que yo quiero; y yo le digo que, cuando no fuera hermano, por ser tan virtuoso y siervo de Dios es mucho para amar. Muy buen alma tiene. Va tornando en sí, que venía muy flaco. Ha sido providencia de Dios hallarme aquí... La Teresa habrá ocho o nueve años, harto bonita y hermosa».

Había consultado a letrados, y le dijeron que, aunque «Teresica» no pudiese tomar el hábito canónicamente hasta los doce años, «mas criarse en el monasterio sí̀, decía a Gracián agradeciéndole sus permisos. «Ya ella está acá con su hábito, que parece duende de casa, y su padre que no cabe de placer, y todas gustan mucho de ella; y tiene una condicioncita como un ángel y sabe entretener bien en las recreaciones contando de los indios y de la mar mejor que yo lo contara» (A Gracián, 27 septiembre 1575). Y hay un retrato, más expresivo por no ser precisamente una obra de arte, de fray Juan de la Miseria (el que retrató también a la Madre Teresa), en el que aparece con hábito de descalza.

Cuando después de casi un año en Sevilla tiene que partir, con su padre y con su tía, hacia Ávila o Toledo, en aquel viaje placentero, era natural que, como escribe la Madre a la priora de Sevilla, fuese «tristecilla, en especial el primer día, decía que de dejar a sus hermanas». Pero nada más llegar al convento de Malagón, «de contento casi no cenó aquella noche que venimos, como si toda su vida hubiera estado con ellas». Y dice que «no la escribe porque está ocupada; dice ella que es priora, y se le encomienda mucho» (A María de San José, 15 junio 1576).

Ya en Ávila la niña, la Madre Teresa desde Toledo comparte con su confidente María de San José (7 septiembre 1576) sus temores a asirse demasiado a ella, la conveniencia de estar separada, pero permaneciendo siempre pendiente de la niña y celebrando su ingenio encantador aunque todavía un poco nostálgico de Sevilla. Se alegra de que entre las monjas de Ávila sea tan querida: «A todas dicen las trae confusas de ver su perfección y la inclinación a oficios bajos. Dice que no piense que por ser sobrina de la fundadora la han de tener en más, sino en menos. Quiérenla mucho, hartas cosas dicen de ella».

Sigue la evolución de la niña. Por medio de su padre le manda un cilicio y una disciplina «que me envió a pedir muy recia» (A Lorenzo de Cepeda, 27-28 febrero 1577). Poco más tarde escribe a María de San José: «iOh, Teresa, qué saltos daba con lo que la envió! Es cosa extraña lo que la quiere. Creo dejaría 
a su padre por irse con ella (con María de San José). Mientras más crece, tiene más virtudes y muy cordecita; ya comulga y no con poca devoción» (4 junio 1577). «Está muy bonita y ha crecido mucho. Encomiéndela a Dios que la haga su sierva (A id. 22 octubre 1577).

Va creciendo, en efecto, tiene ya sus tentaciones, y encuentra en la tía una consejera rebosante de cordura y que le escribe desde Medina (7 agosto 1580): «Y no piense que en viniendo una cosa al pensamiento luego es malo, aunque ello fuese cosa muy mala, que eso no es nada. Cuando algún pensamiento malo le viniere, santígüese o rece un paternóster o dése un golpe en los pechos y procure pensar en otra cosa, y antes será mérito, pues resiste...».

La Madre la llevó a su fundación final de Burgos. En el retorno, en el último viaje, el de la muerte, en el paso por Valladolid hubo algunas tensiones amargas con la priora por cuestiones de herencia, y Teresita pareció inclinarse a la parte contraria a la tía, que, comprensiva, tenía como último proyecto ir a Ávila para allí dar la profesión a la sobrina. Decía, pocos meses antes de morir: «Creo que, siendo Dios servido, me pienso partir en fin de este mes para Palencia, y luego me habré de ir a dar la profesión a Teresa, que se cumple ya el año y ella lo desea ya ver cumplido. Vuestra reverencia y todas la encomienden a Dios este tiempo con mucho cuidado, que la dé Dios su gracia. Miren que lo ha menester, que aunque es bonita, es niña, en fin» (M. María de San José, 14 de julio de 1582). No podría cumplir sus deseos porque el mandato de un superior no muy dotado la obligó a desviar el itinerario en Medina del Campo y a ir a Alba de Tormes para asistir a la duquesa joven que iba a dar a luz; en realidad para morir el 4 de octubre de 1582.

Años atrás, cuando la Madre Teresa estaba en Toledo, se vio precisada a rogar a su hermano que alejara los celillos de la niña: «A Teresa diga vuestra merced que no haya miedo quiera a ninguna como a ella; que reparta las imágenes y no las que yo aparté para mí, y que dé alguna a sus hermanos. Deseo tengo de verla» (2 de enero de 1577).

\section{«LA MI ISABEL»}

Eran explicables los celos de la sobrina niña. Su tía Teresa estaba confinada en Toledo, y allí se encontraba acogida otra niña, la hermanita del padre Gracián, que no era huérfana pero que no podía ser fácilmente atendida por su madre doña Juana Dantisco, que tuvo veinte hijos, de los cuales trece llegaron a la adultez. No daba para mucho el salario del padre, el erasmista Diego Gracián, funcionario real. La niña que se criaba con las monjas de Toledo, con su maestra particular, era Isabel («la mi Isabel», de la Madre Teresa), más o menos de la edad de Teresita. El cariño que siente hacia ella brota a cada paso; y en esa relación de ternura influye indudablemente el afecto hacia el hermano, el padre 
Gracián, empeñado en andar por Andalucía. Se percibe en la correspondencia una especie de pugilato, entablado por la misma Madre, en el que quiere resaltar las cualidades de Bela (que está con ella), comparándolas con las de Teresita, preferida de María de San José en Sevilla.

No se cansa de ensalzar los encantos de «la mi Isabel» a su hermano, un poco desprendido. «La mi Isabel está muy bonita» (9 septiembre 1576), y, de acuerdo con el ideal de belleza: «que está que no hay más que ver de bonita y gorda»; « ¡Oh, qué hermosita se va haciendo! ¡Cómo engorda y qué bonita es!» (A id., 20 septiembre 1576). «La mi Isabel es toda nuestra recreación. Extraña cosa es su apaciblimiento y regocijo» (A id. 23 octubre 1576).

Y era natural que regocijara a las monjas con ocurrencias como la del médico y la clausura tridentina: «La nuestra Isabel está hecha un ángel. Es para alabar a Dios la condición de esta criatura y el contento. Este día acaso salió el médico por una pieza en que ella estaba, que no suele ir por allí. Como vio que la había visto, aunque echó harto a correr, fue su llanto que estaba descomulgada y que la había de echar de casa. Mucha recreación nos da, y todas la quieren grandemente y con razón» (A id., principios diciembre 1576). Y, a propósito de recreación, como el escribir tantas cartas impide a la Madre Teresa asistir a la de comunidad, el que aparezca por ella, «como no es muchas veces», es celebrado como una fiesta por la niña Isabel, que, tal y como cuenta en carta a Gracián en ambiente navideño (finales de diciembre 1576), «deja su labor y comienza a cantar:

$$
\begin{aligned}
& \text { «La madre fundadora } \\
& \text { viene a la recreación; } \\
& \text { bailemos y cantemos } \\
& \text { y hagamos el son». }
\end{aligned}
$$

Lo mejor que puede decir de la niña es su parecido con el carácter de su hermano tan admirado por la Madre y, sin embargo, tan desprendido como le reprocha hasta su hermanita: «La mi Isabel está aquí; dice que cómo le hace vuestra paternidad tantas burlas de no la responder. Dábale de un melón; dice que está muy frío, que le atruena la garganta. Yo le digo que tiene dichos gustosísimos, y una alegría ordinaria y una blandura de condición que se parece harto a mi padre» (A Gracián, 13 de diciembre de 1576).

Con la otra corresponsal principal, María de San José, comparte la misma ternura. Le escribe con la noticia de que han puesto el hábito (a eso de los ocho años) a «la mi Isabelita», que «cuando la pregunté riendo si era desposada, me dijo muy en su seso que sí. Yo le dije que con quién. Díjome que con nuestro Señor Jesucristo muy de presto» (26 noviembre 1576). Pero ante la priora de Sevilla no hace más que resaltar las virtudes de Isabel comparándolas (y no falta 
la grata ironía en las comparaciones) con las de Teresita, que no siempre sale vencedora en este duelo humoroso. Porque la su Bela «es especial y de condición más blanda que Teresa; una habilidad extraña; harto me huelgo con ella» (A María de San José, 13 octubre 1576). El duelo de cariños, entre Bela y Teresita, se describe con humor teresiano y con palabras de antología que merece la pena trascribir porque, además, están escritas para eso, para hacer reír a la destinataria de la carta (A María de San José, 9 enero 1577):

«Donosa está en no querer que sea otra como Teresa. Pues sepa, cierto, que si ésta mi Bela tuviera la gracia natural que la otra y lo sobrenatural (que verdaderamente veíamos obraba Dios algunas cosas en ella), que el entendimiento y habilidad y blandura, de que se puede hacer de ella lo que quisieren, que lo tiene mejor. Es extraña la habilidad de esta criatura, que con unos pastorcillos malaventurados y unas monjillas y una imagen de nuestra Señora que tiene, no viene fiesta que no hace una invención de ello en su ermita o en la recreación, con alguna copla, a que ella da tan buen tono, y la hace, que nos tiene espantadas. Sólo tengo un trabajo: que no sé cómo le poner la boca, porque la tiene frigidísima y se ríe muy fríamente, y siempre se anda riendo. Una vez la hago que la abra, otra que la cierre, otra que no se ría. Ella dice que no tiene la culpa, sino la boca, y dice verdad. Quien ha visto la gracia de Teresa en cuerpo y en todo, echarlo ha más de ver, que así lo hacen acá, aunque yo no lo confieso, y a ella se lo digo en secreto. No lo diga a nadie, que gustaría si viese la vida que traigo en ponerle la boca. Creo como sea mayor no será tan fría; al menos no lo es en los dichos.

Hela aquí pintadas sus muchachas para que no piense que le miento en que hace ventaja a la otra. Porque se ría se lo he dicho. De cuanto trabajo le doy de traer y llevar cartas no haya miedo que yo se le quite. Harto en gracia me han caído».

\section{La niÑa DE ANTONio Gaitán}

Ya más tarde (11 de febrero 1580), cuando las violencias entre calzados y descalzos se han reconducido y todo está más tranquilo, comunica otra vez a Gracián cómo está su Isabel. Y, de acuerdo con el canon de hermosura y de salud vigentes, la encuentra «muy gordita, con unos colores que es para alabar a Dios». Pero también le solicita licencia, como superior, «para la niña de Antonio Gaitán».

Esta niña era Mariana, hija del amigo y colaborador entregado Antonio Gaitán. La Madre Teresa, que la conoció cuando era muy pequeña, de unos cuatro años o menos, la recordaría como «nuestra sabandijita» (A Antonio Gaitán, 10 junio 1575) y a su padre lo llamaría «fundador». El sentimiento de gratitud hacia el entonces viudo y el cariño hacia la criatura lograron todos los permisos, $\mathrm{y}$, por supuesto, Mariana sería admitida para vivir con las monjas en la fundación de su villa, Alba de Tormes, cuando tenía siete años.

Estas licencias eran de esperar; lo que más sorprende es lo que la Madre Teresa dice (y cómo lo dice) de las niñas en los conventos, en un lenguaje que 
quizá hoy no resuene con los mismos acentos que cuando se escribía en ambiente tridentino. La carta salió de Toledo (a mediados de febrero de 1577) buscando al padre Gracián, que, como era habitual, se encontraba por Sevilla. Le dice cómo Antonio Gaitán ha ido a verla, a «pedir se le reciba en Alba su niña, que debe ser como la mi Isabelita de edad». Promete la asistencia económica generosa, pero «lo que ha trabajado por la orden no tiene precio». Lo más interesante es la solicitud, que va mucho más allá de las meras formalidades: «Suplico a vuestra paternidad no me deje de enviar la licencia, por caridad, y presto; que yo le digo que nos edifican estos ángeles y dan recreación. Como hubiese una en cada casa y no más, ningún inconveniente veo sino provecho». ${ }^{27}$

\section{MÁs niÑAS EN LOS CONVENTOS}

De acuerdo con estos deseos de la Madre Teresa, hubo más niñas en las fundaciones teresianas. Concretamente, en la penúltima, la de Soria, estaban dos jovencitas, a las que la fundadora había dado el hábito y saluda en alguna de sus cartas: «A las mis niñas den muchas encomiendas, que harto me huelgo tengan salud y sean tan bonitas». Y niña debía de ser la hija de otro bienhechor entregado, además en la tarea necesaria de redistribuidor de cartas en la corte, Roque de Huerta. Tomaba los negocios de la reforma en sus peores tiempos con tanto interés, que la Madre Teresa tenía que consolarle a él. Y le decía, otra vez agradecida: "Algún día lo podremos servir» (12 de marzo 1579). Y le sirvió, aunque solo hubiera sido con el elogio cariñoso que dejó de su hija en la carta última, la que escribió casi moribunda («porque estamos camino para Medina»). Entre tantos asuntos como trataba con la priora de Soria, no olvidaba estampar el mejor homenaje al padre: «De la hija de Roque de Huerta me huelgo sea bonita» (A Catalina de Cristo, 15-17 septiembre 1582). ${ }^{28}$

\section{CONCLUSIÓN}

Como se puede presumir con facilidad, esta reflexión histórica sobre los sentimientos de la Madre Teresa no agota ni mucho menos el tema, que hemos limitado deliberadamente al sentido del humor y a la ternura. Concluimos con un documento expresivo a más no poder y, además, inesperado en aquel ambiente. Se refiere a la ternura familiar y hacia las niñas, concretamente hacia una niña pequeñísima en edad (da la sensación de ser un bebé) muy especial. Era la hija natural que su sobrino, jovencísimo, Lorenzo de Cepeda había tenido en Ávila. Para confirmar lo que venimos diciendo de lo excepcional del cariño

\footnotetext{
${ }^{27}$ Sobre Antonio Gaitán y su hija, Álvarez, T. (dir). 2002: 920-921.

${ }^{28}$ Sobre Roque de Huerta, Álvarez, T. (dir). 2002: 951-952.
} 
paternofilial, Lorenzo se embarcó para las Indias para aprovechar las rentas de su padre. Naturalmente, dejó a la hija tan tierna en Ávila. Y de nuevo su tía se haría cargo de ella. Confieso mi fracaso en el esfuerzo por conseguir el acta de bautismo con el nombre, algún dato más de esta niña, de la que no quedó más constancia que lo que en la carta comunicaba la Madre Teresa al padre ya en las Indias (A Lorenzo de Cepeda, hijo, en Quito, 15 diciembre 1581). Es emotiva, por la comprensión hacia el desliz del joven, por tanta ternura hacia la criatura inocente, que está allí, en el convento, con ella y con su tía Teresita. Y no se olvide que escribe cuando la queda menos de un año de vida y que es priora de San José, elegida por mayoría (no por unanimidad) de sus monjas y, como dice ella en otra ocasión, «por pura hambre»:

«Harta misericordia de Dios ha sido topar tan bien y haberse casado tan presto, que según de temprano ha comenzado a ser travieso, trabajo tuviéramos. En esto veo lo que le quiero, que con ser cosa para pesarme mucho por la ofensa de Dios, de que veo se parece tanto a vuestra merced esta niña, no la puedo dejar de allegar y querer mucho. Para ser tan chica, es cosa extraña lo que parece a Teresa en la paciencia. Dios la haga su sierva, que ella no tiene culpa; y así vuestra merced no se descuide de procurar que se críe bien, que en habiendo más años, no lo está adonde está; mejor se criara con su tía, hasta ver lo que Dios hace de ella.

Aquí puede vuestra merced ir enviando alguna cantidad de dineros (pues Dios se los ha dado) y que se pongan a censo para los alimentos; de que haya doce años ordenará el Señor lo que se ha de hacer de ella, que es gran cosa criarse en virtud, que ahí se estará el rédito para lo que hubiere de ser de ella. Cierto lo merece, que es agradable, y con ser tan chiquita no querría salir de aquí.

No fuera menester enviar vuestra merced nada para esto, si no es porque esta casa está ahora en gran necesidad; porque murió Francisco de Salcedo, que haya gloria, y dejó aquí una manda, que es poco para tener de comer (que aun para cenar no hay), y luego quitaron casi toda la limosna; aunque andando el tiempo nos irá mejor, que hasta ahora no se ha llevado nada y así se padece harto. Con el dote de Teresa será mucha ayuda, si Dios la deja profesar. Ella harto deseo lo tiene».

\section{BIBLIOGRAFÍA}

Álvarez, T. 1990. «La Madre Teresa habla de fray Juan de la Cruz. Repertorio de textos teresianos sobre el Santo», en Federico Ruiz (coord.), Experiencia y pensamiento en san Juan de la Cruz»: 401-459. Madrid: Editorial de Espiritualidad.

Álvarez, T. (dir). 2002. Diccionario de Santa Teresa. Doctrina e historia. Burgos: Monte Carmelo.

Álvarez, T. 2012. Comentarios a las Cartas de santa Teresa de Jesús. Burgos: Monte Carmelo.

Álvarez, T., Fortes, A. y otros. 1995. Constituciones de las carmelitas descalzas (1562-1607). Roma: Teresianum. 
Ana de San Bartolomé. 1981. «Noticias sobre los comienzos del Carmelo Teresiano», en J. Urkiza (ed), Obras completras de la beata Ana de San Bartolomé, I. Roma: Teresianum.

Ángel de San Gabriel, De la buena mujer Catalina de Cardona: 84v-85r. Manuscrito 4213, BNM.

Arbiol, A. (1715). La familia regulada, con doctrina de la Sagrada Escritura y Santos Padres de la Iglesia Católica, para todos los que regularmente componen una casa, a fin de que cada uno en su estado y en su grado sirva a Dios Nuestro Señor con toda perfección y salve su alma. Zaragoza: Herederos de Manuel Román.

Alonso García, F. 2004. El correo en el Renacimiento europeo. Estudio postal del Archivo Simón Ruiz, 1553-1630. Madrid: Fundación Museo de las Ferias.

Ascandoni Rivero, J. 1999. «El correo durante el reinado de Felipe II», en E. Martínez Ruiz (dir.), Felipe II, la ciencia y la técnica: 253-274. Madrid: Actas.

Atienza, A. 2012. «El mundo de las monjas y de los claustros femeninos en la Edad Moderna. Perspectivas recientes y algunos retos», en E. Serrano Martín (coord.), De la tierra al cielo. Líneas recientes de investigación en Historia Moderna (Ponencias). I Encuentro de Jóvenes Historiadores en Historia Moderna: 89-108. Zaragoza: Institución «Fernando el Católico».

Efrén de la Madre de Dios y Steggink, O. 1977. Tiempo y vida de santa Teresa. Madrid: BAC.

Egido, T. 1981. «El tratamiento histórico de Santa Teresa. Inercias y revisiones», en T. Egido (dir.), Perfil histórico de Santa Teresa: 13-31. Madrid: Editorial de Espiritualidad.

Egido, T. 1983. San Pedro Regalado: Valladolid: Obra Cultural Caja de Ahorros.

Egido, T. 1990. «Los antiguos monjes de San Benito el Real y su rigor fascinante y rentable», en J. Rivera (coord.), Monasterio de San Benito el Real. VI Centenario (13901990): 29-45. Valladolid: Ámbito.

Egido, T. 2000. «Hagiografía y estereotipos de santidad contrarreformista (La manipulación de San Juan de la Cruz)». Cuadernos de Historia Moderna 26: 61- 85.

Egido, T. 2007. «Nuestro Padre San Elías», en F. Millán Romeral (ed.), In labore requies (homenaje de la Región Ibérica Carmelita a los Padres Pablo Garrido y Balbino Velasco): 205-227. Roma: Edizioni Carmelitane.

Fortes, A. y Cuevas, F. J. (eds.). 1991, Procesos de beatificación y canonización de san Juan de la Cruz. II: Procesos ordinarios (1614-1618). Burgos: Monte Carmelo.

Gracián, J. 1982. Escolias a la vida de santa Teresa compuesta por el P. Ribera: (J. L. Astigarraga, ed.). Roma: Teresianum.

Marcos Martín, A. 1993. «San Juan de la Cruz y su ambiente de pobreza», en Actas del Congreso Internacional Sanjuanista, Tomo II: Historia: 143-184. Valladolid: Junta de Castilla y León. 
Montáñez Mantilla, M. 1955. El correo en la España de los Austrias, Madrid: CSIC.

Pacho, E. 1998. «Desde Toledo al Calvario». Teresianum: 49: 607-649.

Portilla y Esquivel, M. de. 1728. Historia de la ciudad de Compluto, vulgarmente Alcalá de Santiuste y aora de Henares. Parte III. Alcalá: Joseph Espartoso.

Rodríguez Martínez, L. y Egido, T. 2002. «Epistolario», en A. Barrientos (dir.), Introducción a la lectura de santa Teresa: 611-667. Madrid: Editorial de Espiritualidad.

Rodríguez, J. V. 2012. San Juan de la Cruz. La biografía. Madrid: San Pablo.

Santa Teresa de Jesús. 2000. Santa Teresa de Jesús. Obras. Madrid: Editorial de Espiritualidad.

Silverio de Santa Teresa (ed.). 1935. Procesos de beatificación y canonización de santa Teresa de Jesús, III: Burgos: Monte Carmelo.

Sobrino Chomón, T. (ed.). 2008. Procesos para la beatificación de la madre Teresa de Jesús. I. Ávila, Institución Gran Duque de Alba.

Tapia, S. de. 2011. «La sociedad abulense en el siglo XvI», en Vivir en Ávila cuando Santa Teresa escribe el libro de su Vida. Ávila: Centro Internacional Teresiano Sanjuanista. 